\title{
Design and Application of Calibration Current Source for UHVDC Current Transformer
}

\author{
Hao Pan ${ }^{1}$, Ke Wang ${ }^{1, *}$, An Wang ${ }^{2}$ and Fangrong Zhou ${ }^{1}$ \\ ${ }^{1}$ Electrical Research Institute of Yunnan Electric Power Research Institute(Group) Co., Ltd., Kunming, 650051 China \\ ${ }^{2}$ College of Electrical Engineering, Southwest Jiaotong University, Chengdu 611756, China \\ ${ }^{*}$ Corresponding author
}

\begin{abstract}
The direct current (DC) current transformers in ultra high-voltage direct current (UHVDC) converter stations have problems such as inconvenient on-site calibration. In order to solve these problems, according to the impedance characteristics of the UHVDC current transformers, the current output scheme for the individual control of multiple current modules is determined. Based on this, a calibration current source is designed, including a DC/DC converter main circuit, a high-frequency transformer, a PWM output control circuit, and a peripheral circuit. The calibration current source has been verified by tests. The results show that the output DC current accuracy is $0.1 \%, 1$ minute stability reaches $0.02 \%$, and accurate regulation can be achieved.
\end{abstract}

Keywords-DC transformer; calibration current source; high frequency transformer

\section{INTRODUCTION}

The UHVDC transmission project has the advantages of large transmission capacity, long transmission distance, low line loss, investment in saving project construction, and reduction of land use area [2][1]. The development of UHV transmission technology can promote the development of coal power, hydropower and nuclear power, and promote the coordinated development of power grid, and achieve the optimal allocation of resources and energy in a wider range [2].

The DC transformer is an important primary equipment of the DC transmission system, providing accurate and reliable measurement information for the control and protection of the system [3]. Its operational reliability and measurement accuracy are directly related to the safety of the HVDC transmission system. In actual operation, some DC transformers suffer from problems such as inaccurate measurements, which has affected all aspects such as energy metering and relay protection, such as excessive output zeros and large differences between channels [4]. Due to the lack of conditions for on-site calibration tests of DC transformers in the past, DC transformers are generally only factory-calibrated. On-site injection tests are only conducted at $10 \%$ of rated current [5]. The on-site calibration test in the full scale range lacks a portable and accurate calibration instrument.

The core of the DC transformer calibrator is the DC current generator, which requires a maximum current amplitude close to $5000 \mathrm{~A} \mathrm{[6]}$. The current generator has a large size and is not easily transported to the site for calibration. In this paper, a modular, easy-to-assemble calibration current source is developed for the characteristics of UHVDC transmission.

The designed calibration current source is used for accuracy verification of DC current transformers for $\pm 800 \mathrm{kV}$ UHVDC converter stations. At present, the maximum rated current of the current transformer used in the $\pm 800 \mathrm{kV}$ UHVDC converter station is $4500 \mathrm{~A}$, and the upper measurement limit can measure up to $120 \%$ of the rated current range. Therefore, it is required that the DC power supply can output at least $5400 \mathrm{~A}$.

The sum of the DC resistance and the lead resistance of a DC transformer generally does not exceed $200 \mu \Omega$. Therefore, when the output current is $5400 \mathrm{~A}$, the required power is $4832 \mathrm{~W}$ and the maximum output voltage is $1.08 \mathrm{~V}$. Taking into account the power consumed by the current measurement resistor, the maximum output power is $9 \mathrm{~kW}$.

The secondary output signal of the DC current transformer needs to be led out from the control room, and the control room is a few hundred meters away from the DC field where the transformer body is located [7]. In order to make the current output from the current source consistent with the reading in the control room, the digital signal should be transmitted to the control room through the field bus after the output current of the current source is sampled.

\section{SYSTEM DESIGN}

\section{A. Design of DC/DC Converter Main Circuit}

The main circuit consists of a power transistor VT, a highfrequency transformer $\mathrm{T}$, and other components, as shown in Figure 1. The breaking of the power transistor VT is controlled by the PWM signal given by the control circuit. When the power transistor VT is turned on, the rectifier diode VD1 is also turned on at the same time. The input power is transmitted to the load through the rectifier diode VD1, and part of the energy is stored in the energy storage inductance L of the output circuit (the secondary circuit of the high frequency transformer). Therefore, this kind of switching power supply is called single-ended forward switching power supply. When the power transistor VT is turned off, the stored energy in the inductor L flows through the load and freewheels through the diode VD2. 


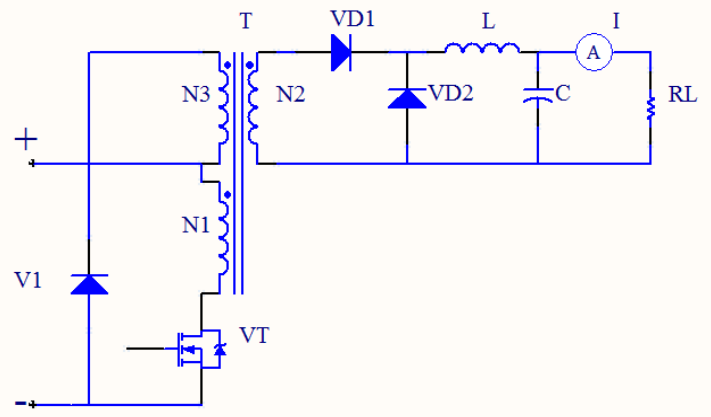

FIGURE I. DC/DC CONVERTER MAIN CIRCUIT

The current flowing in the primary winding of the high frequency transformer $\mathrm{T}$ includes the excitation current in addition to the load current. However, a dedicated winding N3 is also required to demagnetize the excitation flux induced by the excitation current during each switching cycle, that is, the transformer recovers.

The output current is

$$
I_{L}=\frac{N_{2} t_{\text {on }} V_{1}}{N_{1}\left(t_{\text {on }}+t_{\text {off }}\right) R_{L}}
$$

In the equation (1), $\mathrm{N}_{1}$ and $\mathrm{N}_{2}$ are the number of turns of the primary and secondary windings of the transformer; $t_{\text {on }}$ and $t_{\text {off }}$ are the high level time and the low level time of one cycle of the PWM signal; $V_{1}$ is the input voltage. $R_{L}$ is the equivalent load resistance composed of line resistance, transformer resistance and sampling resistance.

In actual operation, the output current value and the actual output current value are compared and set by the control circuit to adjust the duty cycle of the PWM signal. In the circuit, the inductor $47 \mathrm{mH}$, capacitor $100 \mu \mathrm{F}$ and high-frequency-ratio transformer were selected for special design.

\section{B. High Frequency Transformer Design}

Select 9 current modules, each with a power of $1 \mathrm{~kW}$. The output voltage of the $380 \mathrm{~V}$ rectifier circuit is $514 \mathrm{~V}$. Therefore, the transformer primary winding input voltage is $514 \mathrm{~V}$. According to the calculation of the power of a single current output module, the current value of the primary winding is selected as $3 \mathrm{~A}$; the output voltage of the secondary winding is designed as $2 \mathrm{~V}$; the effective value of the current is selected as $600 \mathrm{~A}$; the operating frequency is $20 \mathrm{kHz}$, single-phase pulse.

The low residual magnet-based nanocrystals were selected as the core material. The remanence was $\mathrm{B}_{\mathrm{r}} \leq 0.2 \mathrm{~T}$, and the saturation magnetic induction was $\mathrm{B}_{\mathrm{s}} \leq 1.2 \mathrm{~T}$. Considering that the saturation magnetic induction of the core decreases with increasing temperature (approximately $0.15 \mathrm{~T}$ at $120^{\circ}$ ), the peak value of the one-way magnetic induction increase is $B_{m} \leq 0.7 T$, and the core lamination coefficient is 0.7 . The corresponding pulse width at a frequency of $20 \mathrm{kHz}$ is $50 \mu \mathrm{s}$. The number of primary winding turns is 250 turns. The core cross-sectional area is $\mathrm{S}=\mathrm{UT} /\left(\mathrm{N} \Delta \mathrm{Bk}_{\mathrm{t}}\right) \approx 6.0 \mathrm{~cm}^{2}$. The core cross-sectional area is selected as $20 \mathrm{~mm} \times 30 \mathrm{~mm}$. Core structure size shown in Figure 2.
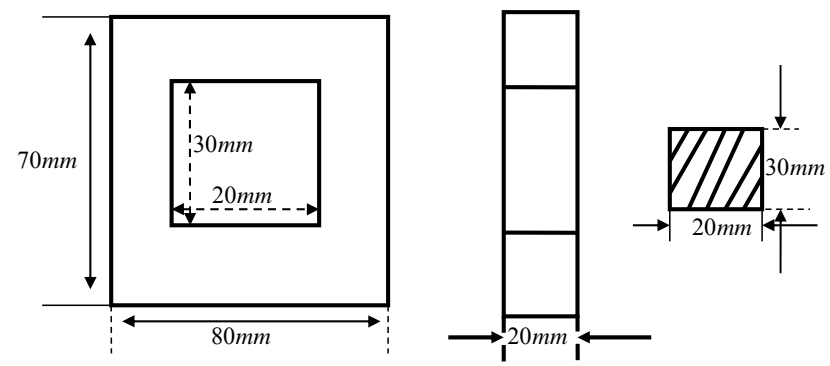

FIGURE II. CORE CROSS-SECTIONAL AREA DESIGN

With a primary current of $3 \mathrm{~A}$, the skin depth of the conductor at a frequency of $20 \mathrm{kHz}$ is $0.467 \mathrm{~mm}$. Taking into account the allowable current density of $5 \mathrm{~A} / \mathrm{mm}^{2}, 2500.5 \mathrm{~mm}$ wire diameter enameled wires are wound in parallel on the primary side and wound in 3 layers.

Consider a primary voltage of $514 \mathrm{~V}$ and a secondary voltage of $2 \mathrm{~V}$, so the transformer voltage ratio is designed to be $250: 1$. The primary current is $600 \mathrm{~A}$. Taking into account the skin depth at $20 \mathrm{kHz}$, a $0.5 \mathrm{~mm}$ copper foil with a width of 25 $\mathrm{mm}$ was used. Transformer core and winding structure shown in Figure 3.
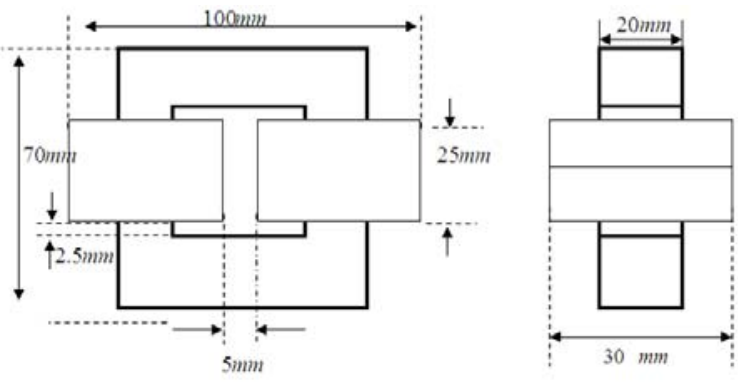

FIGURE III. TRANSFORMER WINDING DESIGN

The SG3525A integrated PWM controller is used as the control chip, as shown in Figure 4. The saw tooth wave generation circuit in the circuit is composed of $R_{T}, C_{T}$ and internal circuits. PWM frequency is selected as $20 \mathrm{kHz}$. This design takes $\mathrm{C}_{\mathrm{T}}=0.1 \mu \mathrm{F}, \mathrm{R}_{\mathrm{T}}=6.6 \mathrm{k} \Omega, \mathrm{R}_{\mathrm{D}}=200 \Omega$. The calculated oscillator output frequency is $19.15 \mathrm{kHz}$.

The current sampling signal is input to pin 1, and is connected to compensation pin 9 through a series capacitor and resistor. The reference signal is converted by the peripheral circuit A/D. The pin 11 output value controls the on/off of the main circuit power transistor VT. The $5.1 \mathrm{~V}$ reference voltage of pin 16 is compared with the current sampling signal after being resistively divided to serve as a current protection signal. 


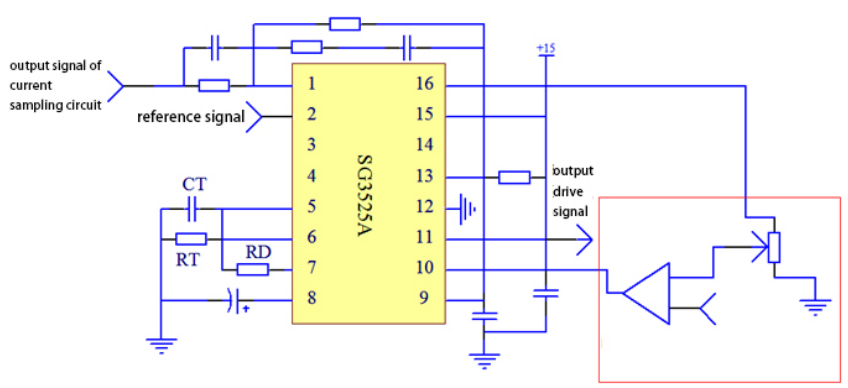

FIGURE IV. THE CONTROL CIRCUIT

The basic functions of the peripheral circuit include:

1. obtain the current output value, and realize humancomputer interaction and communication with other devices.

2. According to actual needs, provide a reference signal. Its structural framework is shown in Figure 4. High-speed 51 single-chip computer (AT891p2052) and CPLD (XC95108PQ100) as the core, supplemented by other circuit modules. It can quickly and effectively collect and process data, and output accurate reference signals in real time.

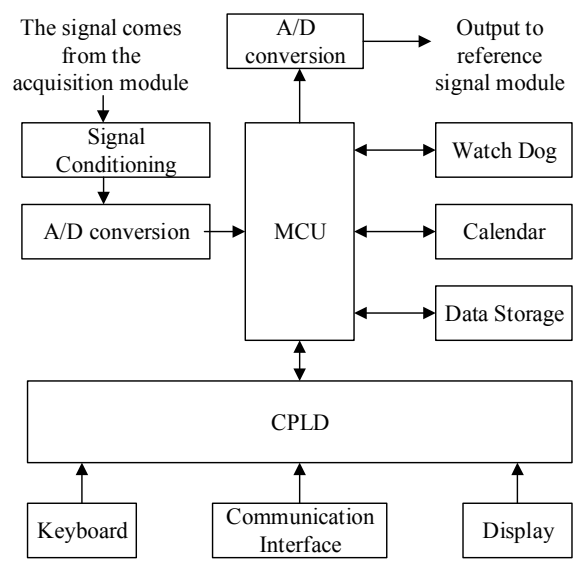

FIGURE V. STRUCTURE OF THE PERIPHERAL CIRCUIT

Xlinks' XC95108PQ100 is used as the main chip of the peripheral interface circuit. Provides standard clocks for microcontrollers and A/D converters. A decoding circuit is provided for the $\mathrm{A} / \mathrm{D}$ converter chip, the display driver chip and the keyboard driver circuit. Provides reliable I/O interfaces for other external control circuits. The data acquisition uses Analog Devices $\Sigma-\Delta$ analog-to-digital converter AD7710 with a resolution of up to $24 \mathrm{bits} / \mathrm{s}$. Using the communication module RS485 method, the signal can be sent synchronously to the main control room to facilitate the simultaneous calibration of multi-transducer. The RS485 driver circuit uses a transceiver SN75LBC184 with transient voltage suppression.

\section{TEST AND EFFECT ANALYSIS}

The designed DC current source for the calibration of the current transformer is verified by tests, as shown in Figure 6. The output DC current accuracy is $0.1 \%, 1$ minute stability reaches $0.02 \%$, and accurate regulation can be achieved.

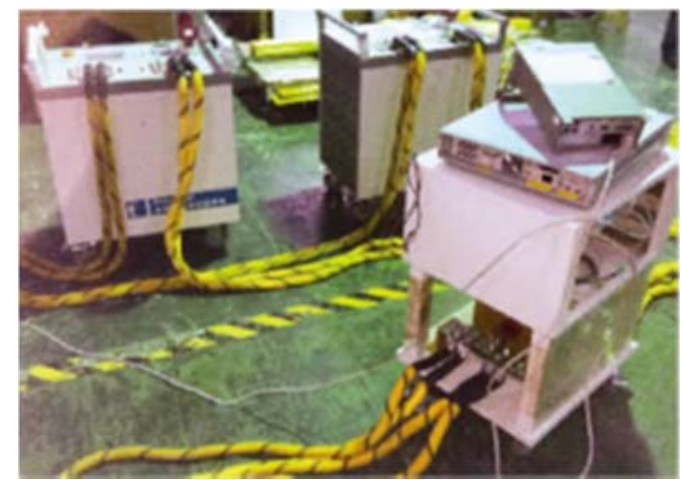

FIGURE VI. TEST

\section{CONCLUSION}

In the past, the conditions for on-site calibration tests of DC transformers were very scarce. At the same time, there were no relevant standards and technical supervision regulations. DC converters for converter stations generally only perform factory calibration. On-site injection testing is only performed at $10 \%$ of rated current. The on-site calibration test in the full scale range lacks a portable and accurate calibration instrument. In order to solve this problem, this article has determined the current output scheme of the individual control of the current module through the impedance characteristic of the UHVDC current transformer. According to the technical solution, a calibration current source is designed, including a DC/DC conversion main circuit, a high-frequency transformer, a PWM output control circuit, and a peripheral circuit. The calibration current source has been verified by tests. The results show that the output DC current accuracy is $0.1 \%, 1$ minute stability reaches $0.02 \%$, and regulation accurately can be achieved.

\section{REFERENCES}

[1] Z. Y. Liu, X. H. Qin, L. Zhao and Q. D. Zhao, "Study on the application of UHVDC hierarchical connection mode to multi-infeed HVDC System," Proceedings of the CSEE, vol.33, Apr. 2013, pp.1-7.

[2] J. Zhang, Y. Y. Hu, F. Liu, X. Y. Yao and J. Yao, "Critical technology of on-site calibration system for DC electronic instrument transformer," High Voltage Apparatus, vol.42, Sep 2016, pp.3003-3010.

[3] W. Yang, J. L. Yang, Y. J. Hou and D. S. Zhang, "Development of $\pm 800 \mathrm{kV}$ DC electronic current transformer," High Voltage Apparatus, vol.47, Jan 2011, pp.10-17.

[4] S. N. Luo, D. M. Cao, Y. Wang, Y. Ding, C. L. Yan, L. Xu and Q. M Shi, "Development and application research of $\pm 800 \mathrm{kV}$ UHVDC fiber optical current transducer," High Voltage Apparatus, vol.52, Oct.16, 2016, pp.1-7.

[5] Q. Li, H. Li, Y. F. Zhou, D. Y .Li, H. L. Hu and S. H. Zhang, "On-site calibration technology of DC current measurement device in converter station of $\pm 800 \mathrm{kV}$ UHVDC transmission project," High Voltage Engineering, vol.37, Dec 2011, pp.3053-3058.

[6] Y. Zhang and H. B. Li, "Reliability prediction of electronic direct current transformer in HDVC system," High Voltage Engineering, vol.33, July 2007, pp.119-123.

[7] Y. Xu, X.T. Han, X. Xiao, H. Rao and Y. Fu, "Skin effect analysis of electronic current transformer in $\pm 500 \mathrm{kV}$," TRANSACTIONS OF CHINA ELECTROTECHNICAL SOCIETY, vol.23, Nov 2008, pp.5358. 